\title{
IDENTIFIKASI SIFAT FISIKO KIMIA MINYAK PALA DARATAN DAN KEPULAUAN DI SULAWESI UTARA
}

\section{PHYSICO-CHEMICAL IDENTIFICATION OF NUTMEG OIL FROM SULAWESI UTARA ARCHIPELAGO AND LAND}

Hilda F.G. Kaseke dan Doly Prima Silaban

Balai Riset dan Standardisasi Industri Manado Jalan Diponegoro No. 21-23

Pos-el : kasekehilda@yahoo.co.id

Diterima Tanggal 03-11-2014, Disetujui Tanggal 17-11-2014

\begin{abstract}
ABSTRAK
Luas areal dan produksi pala di kepulauan di Sulawesi Utara paling banyak terdapat di kepulauan Sitaro, Talaud dan Sangihe dan untuk daratan di kabupaten Minahasa Utara, Minahasa dan Minahasa Tenggara. Pala yang dihasilkan dari kepulauan dan daratan yang ada di Sulawesi Utara umumnya diperdagangkan dalam bentuk biji dan fuli. Untuk mendapatkan mutu minyak pala yang baik dipengaruhi oleh jenis pala, agroklimat lokasi penanaman, umur panen dan teknik penyulingan dalam mendapat minyak pala. Penelitian ini bertujuan untuk mengetahui rendemen minyak pala serta mengidentifikasi sifat fisiko kimia dari minyak pala kepulauan dan daratan di Sulawesi Utara. Penelitian menggunakan metode deskriptif dan dilakukan dalam 2 tahap yaitu menyuling pala untuk mendapatkan minyaknya dan minyak hasil penyulingan diidentifikasi sifat fisiko kimianya. Hasil penelitian menunjukan bahwa rendemen minyak pala kepulauan berkisar 4,89-5,11\% dan pala daratan 4,08-5,01\%. Komponen kimia $\alpha-$ pinen, $\beta$-pinen, limonene, linolool, miristisin pada minyak pala daratan dan kepulauan di Sulawesi Utara memiliki presentase yang berbeda. Kadar miristisin dari minyak pala yang ada di Sulawesi Utara kepulauan berkisar 13,43-16,75\% dan daratan berkisar 11,52-13,54\%. Kadar miristisin tersebut lebih tinggi dari yang dipersyaratkan SNI 06-238-2006 yaitu minimal 10\%.
\end{abstract}

Kata kunci : minyak pala, miristin, fisiko kimia

\section{ABSTRACT}

The biggest total area and production of nutmeg in the archipelago regions of North Sulawesi Provence are located in the Distric of Sitaro, Talaud, Sangihe, while in inland regions are located in the District of North Minahasa, Central Minahasa, and Southeast Minahasa. Nutmeg are generally traded in from of nutmeg and mace. A good quality of nutmeg oil affected by its variety, planting location, harvest age and distillation technique. The research aimed to know nutmeg oil yield and indentify physic-chemical characteristics and main chemical components of nutmeg oil from archipelago and inland regions of North Sulawesi Province. This research used description methods and two stage of processes. First stage was distilling nutmeg to extract the oil and the second stage was analyzing physico-chemical characteristics of the oil. The result showed that yield of nutmeg oil from the archipelago regions was 4.89$5.11 \%$ while that from inland regions was $4.08-5.01 \%$. Nutmeg oil of each area has different quantity of $\alpha$-pinen, $\beta$-pinen, limonene, linolool, myristicin. Myristicin content of nutmeg oil from the archipelago regions was $13.43-16.75 \%$ and that from inland regions was $11.52-13.54 \%$, which was higher than the requirement of $10 \%$ minimal stated in SNI 06-238-2006I.

Keyword: nutmeg oil, myristicin, physico-chemicals

\section{PENDAHULUAN}

Tanaman pala (myristica fragrans Houtt) merupakan tanaman yang buahnya merupakan komoditi perdagangan yang penting. Biji dan fulinya merupakan komoditi ekspor dan banyak dibutuhkan dalam industri kosmetik dan minyak wangi, industri makanan, industri farmasi, bahan pengawet dan industri insektisida. Tanaman pala di Sulawesi Utara sampai 
tahun 2010 seluas 16,031,57 Ha dengan produksi 9,202,80 ton (1).

Minyak pala adalah minyak atsiri yang diperoleh sebagai hasil penyulingan biji, daging dan fuli pala. Minyak pala dapat diperoleh dengan berbagai teknik penyulingan yaitu metode perebusan, pengukusan dan dengan uap langsung.

Minyak atsiri banyak diperlukan dalam kehidupan sehari-hari. Dengan kemajuan teknologi di bidang minyak atsiri, maka usaha-usaha mendapatkan sumber-sumber minyak atsiri dan pendayagunaannya dalam kehidupan manusia semakin meningkat. Minyak atsiri banyak digunakan sebagai obat-obatan. Untuk memenuhi kebutuhan itu, sebagian besar minyak atsiri diambil dari berbagai jenis tanaman penghasil minyak atsiri (2).

Penelitian minyak atsiri dari tanaman pala telah banyak di lakukan untuk menyelidiki manfaat dari tanaman tersebut. Takikawa dkk (3) melaporkan adanya aktivitas antimikroba dari pala. Chattterjee (4) melaporkan adanya aktivitas antioksidan dari fuli pala. Soemani dkk (5) menyatakan bahwa khasiat pala dalam bidang farmakologi antara lain Chemoproticvite, antioxidant, aphrodisiac, antimicrobial, heprotoprotective dan antiinflammatory. Pemanfaatan lain dari minyak pala adalah sebagai bahan campuran pada minuman ringan dan anti mikrobia atau bioinsektisida (6). Luas areal dan produksi pala di kepulauan di Sulawesi Utara paling banyak di kepulauan Sitaro, kepulauan Talaud dan Sangihe. Untuk daratan di Kabupaten Minahasa Utara, Minahasa dan Minahasa Tenggara.
Pala yang dihasilkan dari kepulauan dan daratan yang ada di Sulut, umumnya di perdagangkan dalam bentuk biji dan fuli. Pengolahan minyak pala masih terbatas, padahal minyak dapat diolah dengan menggunakan peralatan yang sederhana.

Minyak pala merupakan salah satu minyak atsiri yang banyak diekspor Indonesia. Ekspor minyak pala Indonesia pada tahun 2011 tercatat sebesar 400 ton dengan nilai USD 24 juta (7). Salah satu indikator mutu minyak pala yaitu kandungan miristin $>13 \%$. Untuk mendapatkan mutu minyak pala yang baik dipengaruhi antara lain oleh jenis pala, agroklimat lokasi penanaman, umur panen dan teknik penyulingan/proses mendapatkan minyak pala.

Sipahelut (8) telah mengidentifikasi minyak dari daging pala di daerah Maluku Tenggara mengandung senyawa $\alpha$-pinen, $\beta$-pinen, terpinen 4-1 dan miristisin.

Berdasarkan potensi cukup banyak di Sulut dan letaknya ada di kepulauan dan daratan, yang pastinya agroklimat mempengaruhi komposisi dari minyak pala, maka perlu dilakukan identifikasi terhadap sifat fisiko kimia dari minyak pala tersebut.

\section{METODOLOGI PENELITIAN}

\section{Bahan-bahan dan Alat}

Bahan yang digunakan dalam penelitian ini adalah biji pala kering yang diambil dari kepulauan dan daratan yang ada di Sulut. Peralatan yang digunakan adalah alat suling pala, timbangan, gelas ukur, thermometer, GCMS 
Metode Penelitian.

Penelitian dilakukan selama 10 bulan, mulai bulan Februari 2014 sampai November 2014, bertempat di Baristand Industri Manado dan Laboratorium di luar Sulut. Penelitian ini dilaksanakan dengan menggunakan metode deskriptif. Penelitian dilakukan dalam 2 tahap, yaitu: menyuling pala untuk mendapatkan minyak pala kemudian hasil minyak pala diidentifikasi sifat fisiko kimianya.

\section{Prosedur Penelitian.}

Biji pala kering di timbang dan di rajang, kemudian dimasukkan dalam alat destilasi air-uap. Minyak yang dihasilkan ditampung dalam botol-botol penampung yang bersih. Minyak hasil destilasi di uji sifat fisiko kimianya.

\section{Pengamatan.}

Pengamatan yang dilakukan yaitu rendemen dengan parameter yang diamati sesuai dengan SNI Minyak Pala (SNI 062388-1988) (9).

\section{HASIL PEMBAHASAN}

\section{Komponen Kimia Minyak Pala Kepulauan dan Daratan di Sulut}

Komponen kimia dari minyak pala dari kepulauan dan daratan yang ada di Sulawesi Utara, dapat dilihat pada tabel berikut ini:

Tabel 1. Komponen Kimia Minyak Pala Kepulauan dan Daratan di Sulut

\begin{tabular}{|c|c|c|c|c|c|c|}
\hline \multirow{3}{*}{$\begin{array}{c}\text { Parameter Uji } \\
(\%)\end{array}$} & \multicolumn{6}{|c|}{ Sampel } \\
\hline & \multicolumn{3}{|c|}{ Kepulauan } & \multicolumn{3}{|c|}{ Daratan } \\
\hline & 1 & 2 & 3 & 1 & 2 & 3 \\
\hline$\alpha$-pinen & 20,36 & 20,57 & 21,27 & 20,37 & 22,56 & 19,67 \\
\hline B-pinen & 20,04 & 22,24 & 18,84 & 20,55 & 20,86 & 21,83 \\
\hline Limonene & 3,95 & 4,07 & 4,02 & 4,22 & 4,40 & 4,02 \\
\hline Linaloal & 0,26 & 0,60 & 0,80 & 0,28 & 0,16 & 0,26 \\
\hline Miristisin & 15,54 & 13,43 & 16,75 & 12,08 & 11,52 & 13,54 \\
\hline & & $\begin{array}{l}\text { 1. Sa } \\
\text { 2. Ta } \\
\text { 3. Si }\end{array}$ & & & Minaha & duk \\
\hline
\end{tabular}

Dari Tabel 1 dapat dilihat bahwa semua komponen penyusun yang diujikan terdapat pada minyak pala baik yang berasal dari kepulauan maupun daratan. Perbedaannya hanya terletak pada presentase komponennya.

Komponen a-pinen dari minyak pala daratan berkisar pada 19,67-22,56\%. Komponen a-pinen terendah dan tertinggi didapatkan pada minyak pala daratan.
Komponen a-pinen dari minyak pala kepulauan berkisar pada 20,36-21,27\%. Komponen $\beta$-pinen minyak pala kepulauan berkisar pada 19,84-22,24\% dan untuk minyak pala daratan dari 20,55-21,83\%. Komponen limonene minyak pala kepulauan berkisar pada angka 3,95-4,07\% dan untuk minyak pala daratan dari 4,02$4,40 \%$. Komponen linalool minyak pala kepulauan berkisar pada angka $0,26-0,80 \%$ 
dan untuk minyak pala daratan dari 0,16 0,28\%. Terdapat angka yang perbedaannya cukup jauh kandungan komponen linalool dari minyak pala kepulauan yaitu $0,60 \%$ dan $0,80 \%$ pada daerah Talaud dan Siau.

Komponen miristisin dari minyak pala kepulauan tinggi dibandingkan minyak pala daratan yaitu $13,43-16,75 \%$ dan 11,5213,54\%. Standar Nasional Indonesia nomor 06-2388-2006 menentukan standar miristin dari minyak pala minimum 10\%, yang berarti bahwa kandungan miristisin dari minyak pala daratan maupun minyak pala kepulauan yang ada di Sulawesi Utara memenuhi syarat mutu sebagai minyak pala. Perbedaan presentase komponen- komponen dari minyak pala daratan maupun kepulauan disebabkan karena pengaruh faktor-faktor lingkungan dan genetik. Robinson (10) menyatakan bahwa minyak atsiri disusun oleh beberapa senyawa kimia yang merupakan hasil reaksi biosintesa dalam tumbuhan. Reaksi tersebut sangat dipengaruhi oleh faktorfaktor lingkungan dan genetik. Dibandingkan dengan komponen kimia pala Banda dan Papua khususnya komponen kimia $\alpha$-pinen, $\beta$-pinen, limonene, linolool, miristisin ternyata pala yang berasal dari Sulawesi Utara baik Kepulauan dan Daratan lebih tinggi presentasenya.

Sifat Fisika Minyak Pala Kepulauan dan Daratan di Sulut

Tabel 2. Komponen Fisika dari minyak pala

\begin{tabular}{|c|c|c|c|c|c|c|}
\hline \multirow{3}{*}{ Jenis Parameter } & \multicolumn{6}{|c|}{ Sampel } \\
\hline & \multicolumn{3}{|c|}{ Kepulauan } & \multicolumn{3}{|c|}{ Daratan } \\
\hline & 1 & 2 & 3 & 1 & 2 & 3 \\
\hline \multirow[t]{2}{*}{ Warna } & Kuning & Kuning & Kuning & Kuning & Kuning & Kuning \\
\hline & pucat & pucat & pucat & pucat & pucat & pucat \\
\hline \multirow[t]{3}{*}{ Bau } & Khas & Khas & Khas & Khas & Khas & Khas \\
\hline & minyak & minyak & minyak & minyak & minyak & minyak \\
\hline & pala & pala & pala & pala & pala & pala \\
\hline Berat jenis $\left(25^{\circ} \mathrm{C}\right)$ & 0,880 & 0,870 & 0,883 & 0,863 & 0,860 & 0,870 \\
\hline Indeks bias $\left(25^{\circ} \mathrm{C}\right)$ & 1,480 & 1,472 & 1,475 & 1,471 & 1,469 & 1,472 \\
\hline Putaran optik & $+26,22^{\circ}$ & $+30,27^{\circ}$ & $+24,03^{\circ}$ & $+31,84^{\circ}$ & $+28,48^{\circ}$ & $+32,10^{\circ}$ \\
\hline Kelarutan dalam & $1: 6$ & $1: 6$ & $1: 6$ & $1: 6$ & $1: 6$ & $1: 6$ \\
\hline alkohol 90\% & Larut & Larut & Larut & larut & larut & Larut \\
\hline
\end{tabular}

\begin{tabular}{|c|c|c|}
\hline $\begin{array}{lr}\text { Keterangan: } \quad \text { Kepulauan } 1 \\
\\
2 \\
3\end{array}$ & $\begin{array}{l}\text { 1.Sangihe } \\
\text { 2.Talaud } \\
\text { 3.Siau }\end{array}$ & $\begin{array}{c}\text { Daratan 1. Minahasa Utara } \\
\text { 2. Minahasa Tenggara } \\
\text { 3. Minahasa Induk }\end{array}$ \\
\hline
\end{tabular}

Warna dari minyak pala yang dihasilkan semuanya berwarna kuning pucat yang berarti memenuhi syarat SNI No. 06-2388-2006 yang mensyaratkan warna dari minyak pala tidak berwarna sampai kuning pucat. Bau dari minyak pala baik yang berasal dari kepulauan dan dari daratan memenuhi syarat mutu minyak pala yaitu berbau khas minyak pala. Kelarutan dalam alkohol 90\% merupakan salah satu sifat fisika yang berhubungan dengan sifat polaritas dan kemurnian minyak atsiri. 
Minyak atsiri yang banyak mengandung komponen-komponen polar akan lebih mudah larut dalam pelarut polar. Dari hasil penelitian minyak pala daratan dan kepulauan yang ada di Sulawesi Utara semuanya sama 1:6 larut yang berarti semuanya memenuhi SNI untuk minyak pala.

Putaran optik merupakan respon struktur molekul terhadap lintasan cahaya gelombang tunggal. Besarnya putaran optik tergantung pada jenis dan konsentrasi senyawa, panjang jalan yang ditempuh sinar melalui senyawa tersebut dan suhu pengukuran (11). Analisis putaran optik digunakan untuk mengetahui kemurnian minyak pala yang disuling. Minyak pala kepulauan dan daratan putaran optiknya berkisar pada $+24,03^{\circ}$ sampai dengan $+32,10^{\circ}$. Standar Nasional Indonesia nomor 06-2388-2006, mensyaratkan bahwa putaran optik berkisar pada $+8^{\circ}$ sampai dengan $+25^{\circ}$ yang berarti dari 6 sampel yang diambil hanya 1 sampel yang memenuhi syarat yaitu sampel dari kepulauan siau putaran optiknya $+24,03^{\circ}$. Hal ini diduga dikarenakan proses penyulingan yang perlu diteliti lebih lanjut untuk mendapatkan kemurnian minyak pala yang lebih baik.

Berat jenis minyak merupakan kumpulan dari berat molekul dari komponen penyusun minyak tersebut dalam volume yang sudah ditetapkan. Standar Nasional Indonesia mensyaratkan berat jenis miyak pala 0,880-0,910 dan dari hasil penelitian terhadap pala kepulauan dan daratan yang ada di Sulut berat jenisnya berkisar pada $0,860-0,883$ yang berarti hanya pala yang berasal dari sangihe dan siau yang memenuhi syarat berat jenisnya yaitu 0,880 dan 0,883

Indeks bias yang disyaratkan pada SNI minyak pala yaitu 1,470-1,497, hasil penelitian didapatkan bahwa kisaran indeks bias dari pala kepulauan dan daratan Sulut berkisar pada 1,469-1,480. Hanya pala yang diambil dari Minahasa tenggara yang tidak memenuhi persyaratan tersebut, sehingga perlu teknik penyulingan yang khusus untuk produk ini.

\section{Rendemen}

Rendemen dari pala kepulauan dan daratan dapat dilihat pada tabel berikut ini.

Tabel 3. Rendemen pala

\begin{tabular}{rlc}
\hline Lokasi & & Rendemen (\%) \\
\hline \multirow{3}{*}{ Kepulauan } & 1 & 5,03 \\
& 2 & 4,89 \\
& 3 & 5,11 \\
\hline \multirow{2}{*}{ Daratan } & 1 & 5,01 \\
& 2 & 4,08 \\
& 3 & 4,39
\end{tabular}


Dari tabel di atas dapat dilihat bahwa rendemen minyak pala kepulauan dan daratan tidak jauh berbeda. Rendemen minyak pala kepulauan berkisar dari 4,89 $5,11 \%$ dan daratan $4,08-5,01 \%$. Rendemen minyak pala tertinggi pada daerah kepulauan yaitu daerah siau yakni $5,11 \%$ dan paling rendah pada daerah minahasa tenggara yaitu $4,08 \%$. Tinggi rendahnya rendemen minyak pala diduga karena letak geografis serta genetik pala tersebut dan teknik penyulingan yang perlu disempurnakan.

\section{KESIMPULAN}

Berdasarkan penelitian diperoleh bahwa rendemen minyak pala kepulauan berkisar 4,89-5,11 \% dan pala daratan 4,08-5,01 \%. Komponen kimia ( $\alpha$-pinen, $\beta$ pinen, limonene, linolool, miristisin) pada minyak pala kepulauan dan daratan memiliki presentase yang berbeda. Perbedaan tersebut menyebabkan karateristik fisik (berat jenis, indeks bias, rotasi optik, dan kelarutan) minyak pala tersebut juga berbeda. Kadar miristisin dari minyak pala yang ada di Sulawesi Utara daratan berkisar 11,52-13,54\% dan kepulauan berkisar 13,43-16,75\%. Kadar miristisin tersebut lebih tinggi dari yang dipersyaratkan SNI 06-238-2006 yaitu minimal $10 \%$.

\section{DAFTAR PUSTAKA}

1. Badan Pusat Statistik. Sulut Dalam Angka. Manado: Badan Pusat Statistik; 1999.
2. Rumondang B. Esterifikasi Patchouli Alkohol Hasil Isolasi Dari Minyak Daun Nilam (Patchouli Oil). Universitas Sumatera Utara; 2004.

3. Takikawa A, Abe K, Yamamoto M, Ishimaru S, Yasui M, Okubo Y YK. Antimicrobial Activity of Nutmeg against Escherichia Coli 0 157. J Biosci Bioeng. 2002;Vol. 94. N:15-320,2.

4. Chattterjee S, Niaz Z, Gautam S, Adhikari S, Variyar PS SA. Antioxidant activity of Some Phenolic Constituents from Green Pepper (Piper nigrum L.) and Fresh Nutmeg Mace (Myristica fragrans). Food Chem. 2007;101:51523.

5. Soemani R, Karve S, Jain D, Jain K SA. Phytochemical and Pharmacological Potential of Myristica Fragrans Houtt: A Comprehensive Review. Pharmacogn Rev [Phcog Rev] -Supplement. Vol 2(4):68-76.

6. Nurdjanah N. Teknologi Pengolahan Pala. Bogor: Badan Penelitian dan Pengembangan Pertanian; 2007.

7. Mulyadi A. Pasar Minyak Atsiri. Pelatihan GMP Minyak Atsiri. Dewan Atsiri Indonesia; 2012.

8. Sipahelut S TI. Karakteristik Minyak Atsiri dari Daging Buah Pala Melalui Beberapa Teknologi Proses. J Teknol Has Pertan. 2011; 
9. Badan Standardisasi Nasional. Minyak

Pala. SNI 06-2388-1988. Badan

Standardisasi Indonesia; 1988.

10. Robinson J. Organic Compound of High Plant. John Willey and Sons; 2000.

11. Guenther E. Minyak Atsiri Jilid 1.

Ketaren S, editor. Jakarta: UI-Press;

1987. 
